
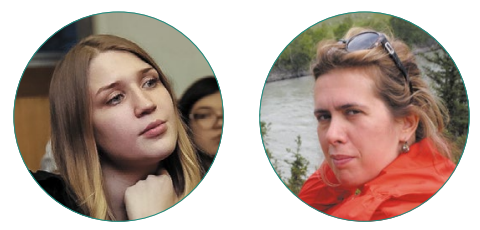

Е. А. Андреева, Л.Б. Карачурина

\title{
СТРАТЕГИИ МИГРАЦИИ ВРАЧЕЙ \\ В ПЕРИФЕРИЙНЫЕ МУНИЦИПАЛЬНЫЕ ОБРАЗОВАНИЯ (НА ПРИМЕРЕ ТВЕРСКОЙ ОБЛАСТИ)
}

\section{Правильная ссылка на статью:}

Андреева Е.А., Карачурина Л.Б. Стратегии миграции врачей в периферийные муниципальные образования (на примере Тверской области) // Мониторинг общественного мнения: экономические и социальные перемены. 2021. № 3. С. 316-338. https://doi.org/ 10.14515/monitoring.2021.3.1725.

\section{For citation:}

Andreeva E. A., Karachurina L. B. (2021) Strategies for the Migration of Physicians to Remote and Rural Areas (on the example of Tver region). Monitoring of Public Opinion: Economic and Social Changes. No. 3. P. 316-338. https://doi.org/10.14515/monitoring.2021.3.1725. (In Russ.) 
СТРАТЕГИИ МИГРАЦИИ ВРАЧЕЙ В ПЕРИФЕРИЙНЫЕ МУНИЦИПАЛЬНЫЕ ОБРАЗОВАНИЯ (НА ПРИМЕРЕ ТВЕРСКОЙ ОБЛАСТИ)

АНДРЕЕВА Екатерина Александровна аспирант, Институт демографии имени А.Г. Вишневского, стажер-исследователь, Институт социальной политики, Национальный исследовательский университет "Высшая школа экономики", Москва, Россия

E-MAIL: Ekaterinaandreeva96@yandex.ru https://orcid.org/0000-0001-5551-6168

КАРАЧУРИНА Лилия Борисовна - кандидат географических наук, доцент кафедры демографии, Национальный исследовательский университет "Высшая школа экономики", Москва, Россия E-MAIL: likaratc@mail.ru https://orcid.org/0000-0001-7760-7925

Аннотация. На основе пятнадцати биографических интервью с переехавшими на периферию врачами, а также восьми интервью с экспертами в сфере здравоохранения, были выделены пять стратегий переезда врачей в нестоличные муниципальные образования Тверской области. Основаниями для выделения стратегий являются выталкивающие и притягивающие факторы переезда и социально-демографические характеристики врачей-мигрантов. Так, стратегия «Где родился, там и пригодился" связана с возвращением врачей в родной населенный пункт для работы сразу после окончания вуза из-за невозможности закрепиться в крупных городах, востребованности межпоколенческой поддержки членов расширенной семьи, а также наличия жилья. "Миграция вслед"- миграция на периферию вслед за супругом или супругой.
STRATEGIES FOR THE MIGRATION OF PHYSICIANS TO REMOTE AND RURAL AREAS (ON THE EXAMPLE OF TVER REGION)

Ekaterina A. ANDREEVA ${ }^{1}-P h D$ Candidate, Vishnevsky Institute of Demography; Research Trainee, Institute for Social Policy

E-MAIL: Ekaterinaandreeva96@yandex.ru https://orcid.org/0000-0001-5551-6168

Liliya B. KARACHURINA1 - Cand. Sci. (Geogr.), Associate Professor, Vishnevsky Institute of Demography, Department of Demography

E-MAIL: likaratc@mail.ru

https://orcid.org/0000-0001-7760-7925

1 HSE University, Moscow, Russia

Abstract. The article identifies five strategies for migration to rural and remote areas of Tver region. The study is based on biographical interviews with fifteen medical doctors who have moved to the periphery as well as on interviews with eight experts in the field of health governing. The revealed strategies result from the interplay between push and pull factors of migration and socio-demographic profiles of migrants. The strategy "Be of use in the place where you were born" is linked with a return migration, particularly if doctors come back to their hometown after graduation from the university because of a lack of resources for life in a big city and the presence of intergenerational transfers."Decembrist wives" - is a strategy of following the spouse to the periphery. Relocation of the "Enforced immigrants" is caused by war, economic or family crisis in their home. Guided by 
"Вынужденных" мигрантов стимулирует для переезда на периферию кризис на родине: военный, экономический, семейный и возможности облегченной по сравнению с региональными центрами адаптации на периферии. В рамках стратегии "Карьеристы" молодых врачей из крупных городов и столичных регионов привлекают возможности получения опыта, а врачей среднего или предпенсионного возраста - получение высокой административной должности. Стратегия "За миллионом" позволяет врачам получить материальное вознаграждение: жилье или компенсационные выплаты. При этом врачи из крупных и столичных городов нередко выбирают перемещения в ежедневном режиме (маятниковую миграцию) - между местом работы, которое является официальным местом жительства для участия в Программе "Земский доктор", и фактическим местом проживания. А врачи, имеющие опыт проживания в нестоличных, малых городах и сельской местности, выбирают переезд на временной или постоянной основе. Для них переезд на периферию связан с меньшими издержками, а существующие программы позволяют улучшить уровень и условия жизни, что увеличивает вероятность закрепления таких врачей-мигрантов на периферии.

Ключевые слова: миграция врачей, профессиональная миграция, внутренняя миграция, миграция в малые города и сельскую местность, модели миграции

Благодарность. Исследование осуществлено в рамках Программы фундаментальных исследований НИУ ВШЭ в 2021 г. the "Careerists" strategy, young doctors from big cities and capital areas are attracted by opportunities for gaining professional experience, while doctors of middle and pre-retirement age are interested in the promotion to the high-level administrative positions. The "Desire of a million" strategy is characterized by receiving material rewards such as housing or compensation payments. At the same time, doctors from big and capital cities often choose to commute between the place of work (which is their official place of residence along with the rules of participation in the "Zemsky doctor" federal program) and the actual place of residence. Doctors who have experienced living in small towns and rural areas often tend to move to the periphery on a permanent or temporarily basis. For them it is associated with lower costs of living - the existing programs allow them to improve the level of life and living conditions. In turn, all these factors increase the likelihood of such doctors becoming entrenched in the periphery.

Keywords: migration of doctors, professional migration, internal migration, migration to small towns and rural area, migration models

Acknowledgments. The study was carried out as part of the HSE University Program of Basic Research in 2021. 
Дефицит медицинских кадров нередко указывается в качестве одного из основных вызовов для современной российской системы государственного здравоохранения [Шейман, Сажина, 2018] ${ }^{1}$. Причины дефицита различны: неравномерность распределения врачей по специализациям, уход врачей из профессии, переход в частные организации, миграция из одного населенного пункта в другой [Комаров, 2013].

До 1990-х годов обеспеченность кадрами в отдаленных и периферийных районах создавалась благодаря распределению специалистов-выпускников. В 2000-е годы кадровая проблема проявилась как острая [Шишкин и др., 2016]. При этом до начала 2010-х годов государство по сути не включалось в решение данного вопроса. C 2012 г. на федеральном уровне начала проводиться политика по стимулированию миграции врачей на периферию: стартовала программа «Земский доктор", в рамках которой врачу, переезжающему для работы на пять лет в сельскую местность или в город с населением меньше 50 тыс. человек, выплачивается 1 млн руб. ${ }^{2}$ Для привлечения молодых специалистов также реализуются программы целевого набора, которые за последние годы претерпели существенные изменения: например, заключение договора нового типа гарантирует возвращение выпускника в место выдачи целевого направления [Регионы дополняют..., 2020]. Однако эффективность проводимых мер для решения проблемы дефицита медицинских кадров на периферии ставится под сомнение [Тарасенко, Хорева, 2016]. Меж тем обеспечение медицинских организаций государственной системы здравоохранения необходимым количеством медицинских кадров-одна из целей национального проекта «Здравоохранение» ${ }^{3}$.

Результаты полевых исследований в Удмуртии (2018г.) и Башкортостане (2019 г.), в которых авторы принимали участие, показывают, что, с одной стороны, привлекательными для миграции врачей в целом остаются региональные центры и столичные регионы России. Это совпадает с общероссийскими тенденциями миграции населения [Карачурина, 2020] и миграционными настроениями, демонстрируемыми выпускниками других специальностей [Козлов, Платонова, Лешуков, 2017].

С другой стороны, и до, и после введения специальных программ находились и находятся специалисты-врачи, которые трудоустраиваются на периферии. Кто эти люди и почему они переезжают вопреки сложившимся миграционным трендам? Фокус данного исследования направлен на изучение миграции врачей,

\footnotetext{
${ }_{1}$ См. также: Рошаль Л. Вызываю врача // Российская газета. 2017. 10 августа. № 7342. URL: https://rg.ru/ gazeta/rg/2017/08/10.html (дата обращения: 25.06.2021); Мануйлова А. Медицинские кадры берут в оборот //Коммерсантъ. 2019. 23 октября. № 194. URL: https://www.kommersant.ru/doc/4134260 (дата обращения: 25.06.2021).

2 Невинная И. Доктор станет ближе // Российская газета. 2019. 8 сентября. № 197. URL: https://rg.ru/2019/09/03/ s-2020-goda-uchastnikami-programmy-zemskij-doktor-stanut-vrachi-vseh-vozrastov.html (дата обращения: 25.06.2021). Возрастное ограничение программы составляет 50 лет, но активно дебатируется вопрос об отмене возрастного ценза. См. Ивушкина А. Медик на миллион: земским докторам отменят возрастной ценз // Известия. 2019. 9 апреля. URL: https://iz.ru/863382/anna-ivushkina/medik-na-million-zemskim-doktoram-otmeniat-vozrastnoi-tcenz (дата обращения: 25.06.2021).

3 Национальные проекты “Здравоохранение» и “Демография». 2018. URL: https://www.rosminzdrav.ru/poleznyeresursy/natsproektzdravoohranenie (дата обращения: 25.06.2021).
} 
переехавших для работы на периферию Тверской области за последние почти десять лет (с 2010 г.).

Описание стратегии миграции врачей будет основано на анализе биографий врачей, которые в настоящее время работают на периферии Тверской области, а также мнений экспертов относительно факторов, которые стимулируют врачей для переезда на периферию.

Тверская область как фокусный для изучения регион была выбрана по нескольким причинам. Во-первых, ее можно рассматривать как "типичный" регион Центрального федерального округа (ЦФО) по особенностям системы расселения и большинству социально-экономических и демографических параметров, [Благовестова, 2013; Вихрев, Ткаченко, Фомкина, 2016; Ткаченко, Фомкина, 2012; Ткаченко, Смирнов, Фомкина, 2015]. Тверская область, как и другие регионы ЦФО, испытывает острый дефицит медицинских кадров. При этом специфика географического положения - между двух столиц и их областей, обладающих ощутимо более высокой миграционной аттрактивностью, - усиливает потенциал миграционного оттока и оборота, а также возможности выбора между мобильностью и оседлостью для населения [Нефедова, Трейвиш, 2013; Мкртчян, 2012]. Во-вторых, его муниципальным образованиям (исключая региональные центры) имманентны характерные для значительной части территории страны проблемы с развитием социальной инфраструктуры [Васильева, 2012; Зубаревич, 2013 и др.]. В этом смысле с некоторыми оговорками можно предполагать, что выявленные для врачей Тверской области миграционные стратегии могут быть свойственны другим регионам европейской части России, исключая пристоличные (Московская и Ленинградская области). Во-вторых, регион имеет масштабную периферийную зону, отличается малоселенностью, демографически старым населением и в целом давними демографическими проблемами. В-третьих, с 1954 г. здесь размещен медицинский вуз (Калининский медицинский институт, затем Тверская государственная медицинская академия). Все это послужило основанием для предположения, что разведывательное исследование миграции врачей на периферии Тверской области поможет выявить стратегии миграции врачей. При этом фокусирование исследования на одном регионе позволит исключить возможное влияние различий региональных политик в привлечении медицинских кадров на существующие стратегии миграции врачей.

Основным предположением исследования является утверждение о том, что стратегии миграции врачей на периферию, с одной стороны, имеют свою специфику, так как для данной профессиональной группы необходим длительный процесс обучения: 6 лет для врачей первичного звена, 8 и более лет - для узких специалистов. В отличие от ряда других секторов экономики в сельской местности и на периферии врачи остаются очень востребованными. Кроме того, существуют государственные программы, которые стимулируют переезд врачей для работы. С другой стороны, выявленные стратегии могут стать основой для изучения факторов, стимулирующих миграцию на периферию в целом, так как наш анализ не ограничивается изучением лишь профессиональных факторов миграции врачей и специальные "профессиональные" факторы и связанные с ними стратегии не могут быть единственно определяющими миграцию. 


\section{Постановка исследовательских вопросов}

В исследовании мы попытаемся ответить на вопросы о том, куда и на какой срок готовы переехать врачи для работы на периферии ${ }^{4}$, что и кто определяет или способствует их решению о миграции, какими социально-демографическими характеристиками они обладают, какие существуют способы ограничения и стимулирования миграции данной профессиональной группы.

Таким образом, цель данной работы состоит в выявлении стратегий миграции врачей в периферийные (нестоличные) муниципальные образования Тверской области.

\section{Предыдущие исследования}

Российские исследователи нечасто уделяют внимание причинам миграции отдельных профессиональных групп. Изучение миграции врачей как в российской [Денисенко, Чудиновских, 2015; Цапенко, Сауткина, 2018], так и в международной традиции [Whittal, Boeckmann, 2018] производится, как правило, на уровне межстрановой смены места жительства и работы [Dubois, Nolte, McKee, 2005; Adkoli, 2006; Goštautaitè et al., 2018; Wismar et al., 2011 и т. д.]: в разрезе анализа миграции врачей из развивающихся стран в развитые [Brugha et al., 2016; Astor et al., 2005; George et al., 2013], из более бедных стран Восточной Европы в Западную Европу [Botezat, Ramos, 2020].

Внутристрановое перемещение медицинских специалистов изучается в странах, для которых актуальны аналогичные проблемы дефицита врачей в сельской местности и в отдаленных районах: Австралии [Han, Humphreys, 2006], Новой Зеландии [Yow, Garces-Ozanne, Audas, 2015], США [Baer et al., 1998], ЮАР [George et al., 2019].

В России проводился анализ миграционных намерений выпускников медицинских вузов [Сиротко, Богатырева, Корендясов, 2015; Оксиненко, 2019], что предполагает исследование потенциальных миграционных установок и мотиваций только определенной возрастной группы. Изучение стимулирующих к миграции на периферию программ производится в основном с точки зрения эффективности государственной политики [Брынза и др., 2017; Тарасенко, Хорева, 2016; Комаров, 2013], лишь частично касаясь объяснения желания или нежелания переехать и работать на периферии тех врачей, которые воспользовались программой “Земский доктор" или переехали на работу по целевому набору [Сиротко, Богатырева, Корендясов, 2015].

Таким образом, научная новизна представленного исследования заключается в изучении факторов миграции российских врачей в малые города, сельскую местность и отдаленные районы и социально-демографических характеристик врачей, ее совершающих.

\section{Теоретико-методологические основания исследования}

Причины, факторы, драйверы, мотивы миграции - понятия, которые имеют близкие по смыслу значения. В литературе они зачастую используются как си-

\footnotetext{
4 Здесь и далее под "периферийными” муниципальными образованиями будут пониматься все нестоличные муниципальные образования Тверской области (городские округа, муниципальные округа, муниципальные районы), вне зависимости от того, как далеко они расположены по отношению к столице региона Твери.
} 
нонимы и в общем смысле показывают то, что побуждает человека к миграции. Разграничение данных понятий производится в нескольких работах [Рыбаковский, 2017; Флоринская, Карачурина, 2018]. Выбранный и используемый в рамках данной работы метод исследования - интервью - не позволяет однозначно установить связь между демографическим событием (миграционным перемещением) и тем, что непосредственно к нему приводит, то есть причиной или детерминантой. Миграция ${ }^{5}$ - это событие, которое совершается под воздействием не какой-либо единичной, пусть и важной причины, а совокупности индивидуальных, семейных, общественных условий, факторов среды исхода и приема, размеров дифференциации объективных условий жизни между местами выхода и вселения [De Haas, 2010: 237]. Поэтому в данном исследовании мы будем подходить к анализу процесса миграции комплексно, то есть стремиться отобразить всю палитру факторов миграции: условий, личных мотивов, дополненных экспертным мнением, которые привели к переезду врача на периферию. Факторы миграции в сочетании с социально-демографическими характеристиками врачей-мигрантов составляют центральное понятие анализа стратегии миграции.

Исследование построено в русле push - pull (“Выталкивания - притяжения») теории. Эта теоретическая рамка исходит из предпосылки, что решение о миграции связано с четырьмя типами факторов: места исхода, места назначения миграции, объективными препятствиями для совершения миграции и личными факторами [Lee, 1966: 50]. В данном случае их можно представить следующим образом. Pull-факторы - это обстоятельства или условия, характеризующие место или условия в месте назначения, то есть на периферии. Push-факторы - это выталкивающие обстоятельства, условия или характеристики места исхода врача, которые создали условия или стимулировали переезд из предыдущего населенного пункта в данный периферийный. Также Э. Ли включает в модель личные факторы (personal factors): некоторые из них постоянны на протяжении жизни людей, другие связаны с отдельной частью жизненного цикла, в частности с резкими изменениям: образование, выход на рынок труда, выход на пенсию, женитьба, развод или смерть супруга. Факторы "препятствий" (intervening obstacles) - это сложности, возникающие в самом процессе переезда. Наиболее изученным и важным фактором «препятствий" является расстояние [Lee, 1966: 51].

В литературе анализ факторов, которые стимулируют и ограничивают миграцию врачей, производится по разным перечням условий переезда. Единого признанного набора анализируемых факторов не существует.

Наиболее распространенный фактор миграции врачей, выделяемый в литературе,- - зарплатный. Разделяют абсолютное или относительное (скорректированное на уровень жизни) превалирование итогового дохода [Astor et al., 2005; Awases et al., 2004; Dubois, Nolte, McKee, 2005; Yow, Garces-Ozanne, Audas, 2015; Комаров, 2013; Оксиненко, 2019]. Исследования показывают, что важен также размер разницы между зарплатами в местах исхода и приема врачей, так как, например, разница между зарплатами в развивающихся и развитых странах настолько большая, что прибавка к зарплате врачей в месте исхода не может

\footnotetext{
5 Под миграцией в интервью мы понимали смену населенного пункта работы и проживания на срок более года.
} 
значимо сократить объем миграции [Vujicic et al., 2004]. Отдельные исследования приводят доказательства того, что значимость зарплатного фактора при принятии решения о миграции врачами переоценивается, более важными являются такие нематериальные факторы, как различия в качестве среды для работы, доступ к новым медицинским технологиям, возможности для карьерного роста, развития навыков и умений [George et al., 2013].

Существуют неденежные факторы миграции врачей, связанные с местом работы, - профессиональные факторы: материальная база, условия труда, ресурсы для эффективной работы, карьерные и образовательные возможности [Dubois, Nolte, McKee, 2005], нагрузка (время, интенсивность работы) [Yow, Garces-Ozanne, Audas, 2015], для молодых специалистов - возможности получения опыта [Syed et al., 2008], наличие среды для применения навыков и реализации профессионального потенциала [Astor et al., 2005].

Выделяются неденежные факторы, связанные с разницей в возможностях мест исхода и приема. Исследования показывают, что в рамках оттока врачей из периферийных территорий значимую роль играют возможности населенного пункта: наличие или отсутствие общей инфраструктуры, мест досуга, образования для детей, рабочих мест для супруга/супруги [Mbemba, Gagnon, Hamelin-Brabant, 2016]. Этот фактор особенно актуален для России из-за ощутимого разрыва между уровнем жизни и возможностями в столичных, центральных городах и периферии, между городским пространством и сельской местностью [Зубаревич, 2017].

Отдельная группа факторов, которые можно назвать "личными", связана с семейными, психологическими причинами миграции или, наоборот, невозможностью миграции в тот или иной населенный пункт [Mbemba, Gagnon, HamelinBrabant, 2016]. В нее входят наличие семьи и друзей, возможности поддержания баланса работы и отдыха, давление социального окружения и семьи для переезда в тот или иной населенный пункт [Akl et al., 2007]. Фактор наличия семьи может оказывать амбивалентное влияние. Исследования показывают, что, с одной стороны, для студентов-медиков значимыми причинами невозвращения в родной населенный пункт могут стать наличие семьи, супруги/супруга и детей и хороший уровень текущего финансового состояния. С другой стороны, наличие детей при отсутствии супруга увеличивает шанс возращения в родной населенный пункт, что связано с возможностью межпоколенческой помощи по воспитанию ребенка. В исследовании В.Г. Оксиненко [Оксиненко, 2019] показано, что при принятии решения о миграции студентами-медиками факторы социального характера (оказание финансовой поддержки семье, наличие детей) оказываются более значимыми, чем для людей других специальностей.

К факторам, которые привлекают врачей для работы именно на периферии и в сельской местности, относят также: выбор определенного стиля жизни, надбавки к зарплате и снижение стоимости жизни [Yow, Garces-Ozanne, Audas, 2015]; лояльность и признание пациентами; положительное восприятие сельского образа жизни: общинный уклад, ценность общения с людьми; наличие социальных связей - друзей, сообщества; поддержка супруга/супруги [Han, Humphreys, 2006]. По данным анкетного опроса молодых врачей-реципиентов программы “Земский доктор" в Самарской области, дополнительными мотивами для переезда стали 
возможности приобретения опыта работы и карьерного роста, желание жить и работать в благоприятных условиях окружающей среды, а также предоставление жилья [Сиротко, Богатырева, Корендясов, 2015].

Выталкивающие из периферии факторы связаны с «непрестижностью и низким статусом сельского врача в профессиональном сообществе; отсутствием качественной образовательно-культурной инфраструктуры и невозможностью дать детям конкурентное среднее образование для последующего получения высшего профессионального образования; найти для замужества равного по статусу человека (актуально для девушек - выпускниц мединститутов)" [Тарасенко, Хорева, 2016].

\section{Эмпирическая база и методы}

Данное исследование выполнено в качественном дизайне с применением метода биографических интервью. Тип выборки - целевой. Преимущество целенаправленного отбора заключается в выборе информационно богатых случаев [Ядов, 1991] - так называют информантов, которые обеспечивают разнообразную и важную информацию о центральных вопросах для достижения цели исследования.

Был применен подход “Восьмиоконной выборки", предложенный И.Е. Штейнбергом [Штейнберг, 2014]. Основу выборки составили «типичные носители практики": врачи, которые переехали для работы в периферийные муниципальные образования Тверской области не более десяти лет назад. Цель описания максимальной палитры возможных стратегий переезда требовала включения в выборку врачей-мигрантов с разными характеристиками и жизненным бэкграундом: переехавших из разных по типу населенных пунктов, обладающих неодинаковыми социально-демографическими характеристиками. В рамках данного "окна" были проведены 15 глубинных биографических интервью с врачами в возрасте от 24 до 50 лет, мужчинами (7 информантов) и женщинами (8 информантов); разной специализации (терапевты, врачи общей практики (ВОП), педиатры, стоматологи, психиатры, хирурги, невропатологи, дерматовенерологи и др.). Основу выборки составили врачи первичного звена. В выборку попали представители разных типов медицинских учреждений - относительно крупных (для периферии) центральных районных больниц в городах и сельской местности, поликлиник, сельских врачебных амбулаторий (офисов ВОПов.)

Для получения контрастных случаев в выборку также были включены информанты, отражающие два других окна. Во-первых, специфичный информант, который совпадает по всем характеристикам с типичным носителем практики, но отличается по критерию наличия опыта переезда на периферию. В рамках данного исследования им стал выпускник медицинского вуза, поступивший в вуз из периферии области, который не поехал работать обратно на периферию. Вовторых, маргинальный информант - носитель целевой практики, “отличающийся от типичного представителя рядом характеристик, например, полом, возрастом, материальным положением, личностными чертами" [Штейнберг, 2014: 62]. Таким респондентом стал врач, который работает в медицинском учреждении на периферии и имеет опыт переезда, но переезд был совершен до 2010 г. 
Кроме того, личные истории миграции врачей на периферию были дополнены экспертными мнениями. В рамках "окна" экспертных респондентов были проведены 5 глубинных интервью: 4 - с работниками медицинских учреждений (в том числе руководящего и административного звена, кадровой службы), и 1 - с сотрудником Тверского государственного медицинского университета (ТГМУ).

Повторение сюжетов в нарративах информантов и подтверждение экспертным мнением полученной эмпирической схемы дают нам основание полагать, что в процессе полевого этапа были собраны исчерпывающие данные о миграции врачей на периферию Тверской области.

Поиск информантов осуществлялся с помощью нескольких каналов: социальной сети "ВКонтакте»; поиска по месту работы; через личные знакомства; методом снежного кома.

Для проведения интервью были разработаны два гайда: для врачей и для экспертов. В соответствии с методом биографического интервью вопросы гайда для врачей направляли информанта на полноценный рассказ о его жизни до и после переезда, а также на рефлексию относительно всех сторон его жизни, тем самым раскрывая детали процесса миграции. Вопросы гайда для экспертов строились вокруг обсуждения дефицита кадров, эффективности государственных программ, а также их мнения относительно возможных причин приезда их коллег для работы в периферийных медицинских учреждениях и т.д.

Анализ интервью произведен в логике тематического кодирования - в тексте интервью в процессе открытого кодирования были выявлены все ключевые выталкивающие и притягивающие факторы, которые затем агрегировались в содержательные субкоды (факторы). Пересечение факторов в сочетании с выявленными индивидуальными и средовыми характеристиками, сопутствующими миграции, были положены в основу эмпирических аналитических схем (стратегий).

\section{Основные результаты}

В результате исследования были выделены пять стратегий переезда врачей для работы на периферии, сочетающих в себе мотивирующие для переезда на периферию факторы, и соответствующие стратегиям социально-демографические портреты врачей.

"Где родился, там и пригодился". "Возвращенцы"

По мнению экспертов и информантов, самая распространенная модель переезда врачей для работы на периферию-это возвращение в населенный пункт исхода. Чаще всего переезжают врачи в возрасте 24-30 лет, возвращаясь после выпуска из вуза в место их предыдущего проживания и в место проживания их родителей из-за невозможности закрепиться в городе или желания получить базовый профессиональный опыт и навыки.

Bce, кто работает врачом на районах, [приезжают] не то, чтобы из-за денег. Да, они знают об этом и подают заявки [на программу “Земский доктор»]. Но в основном это люди возвращаются к родителям или не могут закрепиться в каком-то большом городе. (Эксперт-стоматолог, 34 года, мужчина) 
При возвратной миграции важным фактором выступает межпоколенческая поддержка членов расширенной семьи:

- Для выпускников медицинских вузов из семей с низкими доходами - материальная помощь родителей, наличие жилья.

- Для семей врачей с маленькими детьми - помощь в уходе за ребенком, позволяющая раньше выйти на работу. Это подтверждает описанную в исследовании В.Г. Оксиненко [Оксиненко, 2019] зависимость между возвратной миграцией и наличием детей.

Другим фактором, стимулирующим возвращение в "родной" населенный пункт, является отработка целевого направления, которые выдаются только "местным" выпускникам, чтобы помочь им преодолеть высокий порог баллов ЕГЭ при поступлении в медицинский вуз. Возможность получения бесплатного медицинского образования в специалитете и ординатуре стимулирует выпускников школ периферийных населенных пунктов заключать договоры на обучение с обязательством отработки трехлетнего срока в медицинских учреждениях районов Тверской области, выдававших соответствующие направления. Это и определяет контингент "пользователей" данной стратегии.

Эксперты отмечают, что портрет "типичного целевика" изменился в последнее время, так как увеличился набор по целевым программам, а значит, у большего количества школьников появилась возможность воспользоваться данной программой. Раньше, по мнению экспертов, это было привилегией детей медицинских работников и администрации муниципальных образований. Кроме того, доля возвращающихся по целевым программам выросла. Появились сначала договорные, а потом материальные обязательства отработки трехлетнего срока, что привело к более высокой востребованности программы у детей из малообеспеченных слоев населения в сравнении с прошлыми реципиентами программы. Для школьников с периферии программа часто является единственной возможностью получить бесплатное высшее образование, и их не пугает необходимость возращения в родной населенный пункт. В то же время более богатые семьи могут оплатить подготовку к экзаменам или обучение в медицинском вузе, не обременяя себя обязательствами работы в "домашнем" медицинском учреждении.

\section{Миграция "вслед"}

Важная категория факторов, стимулирующих переезд на периферию, - семейные обстоятельства. Этот тезис подтверждается исследованием В.Г. Оксиненко [Оксиненко, 2019], в котором показано, что семейные факторы более важны для выпускников медицинских вузов, чем для других специальностей.

Данная стратегия универсальна для всех типов миграции по направлению перемещения: вертикальной (из столичных регионов и крупных городов на периферию) и горизонтальной (внутри периферии из одного населенного пункта в другой населенный пункт). То есть для определенной части врачей не имеет особого значения, из какого пункта в какой они переселяются, потому что эта стратегия связана с миграцией вслед за супругом/супругой, отчасти носящей вынужденный характер. Выбор населенного пункта в этом случае не зависит от профессиональных факторов или личного выбора, он вторичен по отношению к семейно-личной истории человека. 
Представители данной стратегии чаще всего женщины. Их возраст совпадает с текущими трендами наиболее активных "брачных" возрастов, с возможной поправкой на возраст выпуска из медицинских вузов, а именно 24-35 лет ${ }^{6}$.

Здесь важной особенностью врачей выступают высокие возможности для их трудоустройства в любом населенном пункте, поэтому момент “следования" и некоей "Вынужденности" для них менее болезненный, чем для представителей других специальностей, чье трудоустройство зависит от емкости и дифференцированности рынка труда. Как показали полевые исследования в Удмуртии (2018 г.) и Башкортостане (2019 г.), в которых автор принимал участие, на рынках труда периферийных населенных пунктов схожую с врачами ситуацию имеют только учителя.

Поэтому я мужу дала добро искать работу, где угодно. Лишь бы работал и работа ему нравилась. А я работу найду. (ВОП, сельский населенный пункт, 27, ж.)

"Карьеристы» - профессиональный и административный рост

Данная стратегия миграции связана с менее конкурентным рынком труда медицинских специальностей на периферии, как следствие - с более высокими возможностями для получения первичного опыта, профессионального и карьерного роста. Особенностью данной стратегии является то, что ее представители часто выходцы из крупных городов, из региональных центров.

Если мы ищем куда-либо в больницу специалиста уровня руководителя больницы, из Твери и Московской области желающих очень много. (Эксперт по государственным программам, 50, ж.)

Возможность получения опыта привлекает в основном молодых специалистов, недавних выпускников медицинских вузов.

Хотя бы для начала опыта набраться. Потому что сейчас везде идет тенденция по Тверской области: большие больницы стараются людей не брать, если у них нет опыта работы на селе. (Стоматолог, сельский населенный пункт, 35, м.)

Данный фактор актуален для двух категорий молодых специалистов - врачей: представителей специальностей с высокой насыщенностью рынка в крупных городах (например, стоматологов и хирургов) - для них работа на периферии дает возможность доступа к операциям, реальной практике, то есть к тому, что в их узкой профессиональной нише трудно обеспечить в большом городе. При этом важно, чтобы периферийное медицинское учреждение обладало необходимым оборудованием и материалами, а также специалистами-наставниками. Другая группа - врачи таких специальностей, для работы которых не требуется наличия диагностического оборудования, специальных возможностей медучреждения например, врачи общей практики, психиатры.

\footnotetext{
6 Щербакова Е. М. Предварительные демографические итоги 2019 года в России (часть I) // Демоскоп Weekly. 2020. № 847-848. URL: http://www.demoscope.ru/weekly/2020/0847/barom01.php (дата обращения: 26.06.2021).
} 
Работа нравится, но тяжелая. У нас самое оперирующее отделение. Но и знания, навыки. Столь колоссального опыта без блата сейчас не найти нигде. Да и с блатом, думаю, тоже. (Хирург, город, 30, м.)

Еще одна "карьерная" группа, причем в реальном понимании этого термина это одинокие (часто) врачи с опытом, старшего и предпенсионного возраста (после 40), желающие получить на периферии управляющие должности.

Это, конечно, не молодые люди уже, те, кому за 40-ну вот приезжают на собеседования в Минздрав, что да, “хочу быть главным врачом в этой больнице». (Эксперт по государственным программам, 50, ж.)

\section{Вынужденные мигранты - кризис на родине}

(экономический, семейный, военный)

Выделение этой категории связано с тем, что для мигрантов, следующих данной миграционной стратегии, главными являются факторы, выталкивающие их с места исхода (например, невозможность обеспечивать семью на родине, где наблюдается сложная экономическая ситуация или идет война, развод). Притягивающие же на периферию факторы могут разниться для разных категорий мигрантов.

1. Международные мигранты.

На периферию Тверской области для работы переезжают врачи из других стран. Такая стратегия переезда мигрантов-врачей и их оседание в сельской местности является общемировым трендом: например, в США в сельской местности, где существует проблема дефицита медицинских специалистов, он компенсируется выпускниками международных медицинских вузов [Baer et al., 1998], в Австралии существует правило, согласно которому выпускники с международными дипломами при устройстве на работу в стране должны проработать пять лет в отдаленных сельских территориях с дефицитом врачей [Han, Humphreys, 2006].

По мнению экспертов, объем и география потоков врачей-мигрантов на периферию Тверской области различаются по периодам. В начале 2000-х годов больший поток мигрантов происходил из стран Средней Азии, после 2014 г., в связи с событиями в Украине, стали больше приезжать из Донецкой и Луганской областей.

Факторы, которые притягивают врачей для работы именно на периферию, связаны с более доступной в материальном плане жизнью, жильем, более дефицитным и менее конкурентным, чем в крупных городах страны, рынком труда. Все это делает трудоустройство более быстрым и простым, а адаптацию-более легкой. При этом для врачей - международных мигрантов периферия часто выступает «трамплинной зоной" для дальнейшего переезда.

Они вообще наш город и вообще нашу область расценивали как “перевалочный пункт»: немножко побыть тут и ехать дальше (это от года до, может быть, трех лет. Так, около того). Они тоже хотят в больших центрах быть. (Эксперт-педиатр, 52, ж.) 
Если говорить о push-факторах переезда врачей из стран бывшего СССР для работы в Россию в целом, исследователи выделяют более высокий уровень зарплат; признание дипломов, полученных до распада СССР, и упрощенный режим подтверждения диплома, полученного в постсоветское время [Денисенко, Чудиновских, 2015]. Так, в 2014 г. был утвержден ускоренный процесс нострификации документов для мигрантов из Украины (3 дня в сравнении с традиционными 30 днями для других международных мигрантов). Действуют также такие факторы, как более простой процесс адаптации, понимание условий жизни, отсутствие языкового барьера, наличие личных связей, оставшихся еще со времен СССР.

Опять же белорусов в основном привлекает [переезд] именно финансово, потому что зарплаты совсем другие. (Эксперт-стоматолог, 34, м.)

Рассмотрим подробнее особенности миграции врачей из разных категорий стран.

Вынужденные мигранты из Украины в 2014 г. (Луганск, Донбасс). При выборе для переезда населенных пунктов, находящихся на периферии, действуют два фактора:

- выталкивания из областных центров - получить там миграционные документы затруднительно;

- притяжения - место переезда выбиралось, исходя из наличных социальных контактов, так как это упрощало процесс переезда и адаптации.

В основном, когда люди переезжали, им в областном центре не удавалось даже, скажем, оформить эти документы миграционные, поэтому они в любом случае ехали сначала на периферию. (Психиатр, город, 39, м.)

При этом, по словам врача-мигранта из Луганска, основным фактором, который способствовал его закреплению на периферии, было прежде всего предоставленное жилье и финансовая невозможность покупки или аренды жилья в более крупных городах.

В связи с вынужденным характером миграции переезд осуществляется расширенными семьями.

Да, я переехал с семьей, с женой, с ребенком, тещу еще привез на время. Так и живем. (Психиатр, город, 39, м.)

Мигранты из стран Средней Азии "закрывают" в основном особенно дефицитные специальности: хирурги, реаниматологи, анестезиологи.

По мнению экспертов, более распространен переезд для работы мужчин среднего возраста. Однако это не является характеристикой миграции только на периферию. По данным исследования М. Денисенко и О. Чудиновских, "портрет" мигрантов, которые прошли процесс нострификации диплома в России, выглядит так: это мужчины, трудоспособного возраста, главным образом 30-49 лет [Денисенко, Чудиновских, 2015]. 
Работа на периферии граждан стран СНГ имеет две формы: долгосрочная миграция врача с семьей для жизни на периферии Тверской области (рассматриваемой как временное пристанище или навсегда); переезд главы семьи на заработки в Россию, при котором семья остается жить на родине.

2. “Беженцы” по личным причинам.

Совсем иную, но также решающую роль для переезда врача на периферию выталкивающие причины играют в случае определенных жизненных и личных ситуаций, которые требуют смены места жительства. К ним относятся развод, конфликты на работе или дома, увольнение с предыдущего места работы из-за девиантного поведения и пр.

Информанты говорят, что развод является значимым выталкивающим фактором из крупных городов, так как возникает необходимость разъезда с супругом, освобождения жилья, а иногда к материальным проблемам, связанными с этими событиями, добавляется желание "убежать" в другой город. Из-за более дефицитного рынка труда и возможностей получить квартиру или "заработать миллион" врачи нередко выбирают в таком случае переезд на периферию.

Первая семья-то у меня в Москве осталась. Жизненные обстоятельства сложились так, что я уехал сюда в деревню. И здесь уже обзавелся новой семьей. (Стоматолог, сельский населенный пункт, 35, м.)

Представители данной стратегии - в основном одинокие мужчины среднего возраста (35-55 лет). Эта стратегия миграции может быть использована как выходцами из крупных и столичных городов, так и для горизонтальной миграции из одного периферийного населенного пункта в другой периферийный.

\section{“За миллионом" - улучшение материального положения}

Одна из стратегий переезда врачей на периферию мотивируется получением определенных преференций: приобретением дополнительных жизненных возможностей и улучшением материального положения, связанных с использованием государственных программ. Это программа компенсационных выплат («Земский доктор"), выделение служебного жилья/софинансирование аренды жилья.

Программы предоставления служебного жилья или получения миллиона по программе "Земский доктор" востребованы у врачей, работающих на периферии. Молодые семьи для получения возможности решить свои жилищные проблемы переезжают из одного населенного пункта, находящегося в периферийном районе, в другой - для них это возможность заработать миллион и, возможно, вернуться обратно или закрепиться недалеко от "родных" мест.

Дополнительным преимуществом для совершения такой миграции является работа супруга врача в бюджетной сфере: тоже врачами, средним медперсоналом, учителями, полицейскими и т.д., так как данные профессии так же высоко востребованы на периферии. При этом, если супруг тоже работник системы здравоохранения, для него предусмотрена возможность получения двойной выплаты по программе «Земский доктор». 
Более высокий спрос на участие в Программе у врачей из периферии можно объяснить тем, что миллион рублей для жителей крупных городов представляет меньшую "ценность", чем для жителей малых городов и сельской местности. Кроме того, если исходить из "полезностного" подхода к анализу миграции, решение о переезде принимается путем сравнения "выигрыша" от миграции с теми издержками, которые необходимо понести [Harris, Todaro, 1970]. Для врачей, имеющих опыт проживания или проживающих в данный момент не в столице Тверской области, издержки по переезду меньше, так как не происходит кардинальной смены их стиля жизни, сохраняется привычный социальный круг (выбор близкого от "родного" населенного пункта с хорошим доступом к родным и знакомым, возвращение в "родной" сельский или периферийный населенный пункт после долгого проживания в городе или в столице региона). К таким же выводам приходит исследование выпускников медицинского вуза ЮАР: опыт проживания в сельской местности у студентов увеличивает вероятность их согласия на переезд для работы в отдаленных сельских районах с кадровым дефицитом [George et al., 2019].

Одной из форм реализации участия врачей в программе "Земский доктор" является маятниковая миграция, то есть ежедневный приезд на работу врачей из других населенных пунктов. Маятниковая миграция - форма мобильности населения, но не миграция в узком понимании. Нам, однако, представляется важным описание данной стратегии, так как нашей целью является описание максимально возможной палитры вариантов.

Данная стратегия осуществляется, когда врач не имеет возможности, не видит необходимости или не имеет желания перебраться в населенный пункт работы.

В основном участвуют взрослые, семейные люди, у которых вопрос жилья уже в Твери решен, они могли себе позволить как-то временно зарегистрироваться там, или на машине, если это Калининская ЦРБ или Конаковская - час в пути, и ты на работе. (Эксперт по государственным программам, 50, ж.)

При данном формате работы действует фактор территориальной близости места проживания и работы. Главный стимул к выбору такой формы проживания-работы - экономический: более высокая зарплата (горизонтальная миграция из периферии на периферию) или получение компенсационной выплаты по "Земскому доктору" (горизонтальная миграция и вертикальная из регионального центра или из более крупного населенного пункта в менее крупный).

Для выходцев из крупных и столичных городов, воспользовавшихся программой "Земский доктор", часто ключевым для выбора данного формата миграции становится временный характер трудоустройства: получить деньги, отработать пять лет и вернуться на работу в свой населенный пункт. При этом для данной группы частый сценарий - возврат части денежных средств раньше срока отработки, необходимого для получения миллиона, из-за сложностей адаптации для таких мигрантов к новым условиям жизни. Так как все, что их удерживает в данном населенном пункте,- это деньги, которые при возникновении дополнительных сложностей и трудностей теряют высокое значение. 
Семейная одна ездила на машине каждый день туда-обратно. Я думаю, она ездить устала, - мое мнение. (Эксперт, заместитель глав. врача, 48, ж.)

\section{Заключение и дискуссия}

Наши результаты подтверждают выводы зарубежных исследований о миграции врачей в отдаленные районы и сельскую местность [Mbemba, Gagnon, HamelinBrabant, 2016; Yow, Garces-Ozanne, Audas, 2015; Han, Humphreys, 2006] и показывают, что pus - pull факторы, определяющие стратегии миграции врачей на периферию, во многом совпадают с факторами, характерными для миграции в целом: действуют семейные, личные, экономические, средовые и другие причины. Специфическими факторами, определяющими миграцию врачей на периферию, являются наличие и действие государственных программ, возможности быстрого карьерного роста и получения опыта, широкая вариативность выбора населенного пункта для работы и проживания в соответствии с личными предпочтениями в связи с почти повсеместным наличием мест приложения труда для врачей на периферии. Кроме того, выявились соответствия с жизненным циклом: молодых врачей на периферию привлекают возможности получения опыта и межпоколенческих трансфертов (экономических и инструментальных); молодые семьи - возможности получения жилья и улучшения условий жизни; врачей среднего и предпенсионного возраста - карьерный потенциал или возможности смены стиля жизни на более спокойный. Все это показывает, что социо-демографические характеристики врачей и соответствующие им мотивации во многом совпадают с общими стратегиями миграции [Население России..., 2019].

Наиболее востребованной для переезда на периферию Тверской области стратегией является возвратная миграция в населенный пункт исхода, что подтверждает выводы В.Г. Оксиненко [Оксиненко, 2019], М. Л. Сиротко с коллегами [Сиротко, Богатырева, Корендясов, 2015] о превалировании социальных факторов в определении миграционных намерений студентов медицинских специальностей, сделанные на основе принципиально иных данных и методов. Нам удалось также выявить, что меньшие трудности в переезде на периферию испытывают те врачи, у которых был опыт проживания и (или) работы на периферии.

В анализируемых нами исследованиях авторы, предлагая способы улучшения существующей политики по привлечению врачебных кадров для работы на периферию, чаще всего указывают на необходимость увеличения размера компенсационных выплат, расширение возрастного ценза участников программы или же ограничение возможностей траты компенсационных выплат (например, только на покупку жилья в конкретном населенном пункте) [Сиротко, Богатырева, Корендясов, 2015; Тарасенко, Хорева, 2016]. Полученные в данном исследовании результаты свидетельствуют о том, что фокус государственных программ должен быть смещен с привлечения врачей из областных центров и крупных городов на привлечение и удержание тех врачей, у которых уже есть опыт проживания и работы на периферии. Представляется, что этот вывод может стать важным дополнительным ориентиром для разработки и уточнения мер государственной политики в области решения проблемы дефицита врачей на периферии. 


\section{Список литературы (References)}

Благовестова Т.Е. Типология регионов Центрального федерального округа по уровню развития социальной инфраструктуры в 1990-2013 гг. //Региональные исследования. 2015. № 4. C. 24-33. URL: http://media.geogr.msu.ru/RI/RI_2015_04(50). pdf (дата обращения: 26.06.2021).

Blagovestova T.E. (2015) Typology of the Regions of the Central Federal District in Terms of 1990-2013 Social Infrastructure Development Level. Regional Studies. No. 4. P. 24-33. URL: http://media.geogr.msu.ru/RI/RI_2015_04(50).pdf (accessed: 26.06.2021). (In Russ.)

Брынза Н. С., Горбунова О.П., Сунгатуллина Л. А., Кинчагулова М. В., Литвинов И.С., Суханова Т.В. Исследование факторов мотивации участников программы «Земский доктор" в Тюменском муниципальном районе // Медицинская наука и образование Урала. 2017. T. 18. № 1. С. 88-91. URL: https://www.tyumsmu.ru/ science/scientific_journals/medical_science_and_education_in_the_urals/archive/ two-thousand-seventeen / (дата обращения: 26.06.2021).

Brynza N. S., Gorbunova O. P., Sungatullina L. A., Kinchagulova M. V., Litvinov I. S., Sukhanova T. V. (2017) Research of Motivation Factors of the "Zemsky Doctor" Program Participants in the Tyumen Municipal District. Ural Medical Science and Education. Vol. 18. No. 1. P. 88-92. URL: https://www.tyumsmu.ru/science/scientific_journals/ medical_science_and_education_in_the_urals/archive/two-thousand-seventeen/ (accessed: 26.06.2021). (In Russ.)

Васильева О.Е. Территориальная организация медицинского обслуживания в сельской местности республики Башкортостан // Вестник Московского университета. Серия 5. География. 2012. № 2. С. 76-81.

Vasilyeva O. E. (2012) Territorial Organization of Medical Services in Rural Areas of the Bashkortostan Republic. Moscow University Bulletin. Series 5. Geography. No. 2. P. 76-81. (In Russ.)

Вихрев О.В., Ткаченко А. А., Фомкина А. А. Системы сельского расселения и их центры (на примере Тверской области) //Вестник Московского университета. Серия 5: География. 2016. № 2. С. 30-37. URL: https://vestnik5.geogr.msu.ru/ jour/article/view/202?locale=ru_RU (дата обращения: 26.06.2021).

Vikhrev O.V., Tkachenko A. A., Fomkina A. A. (2016) Rural Settlement Systems and Settlement Centers (Case Study of the Tver Oblast). Moscow University Bulletin. Series 5. Geography. No. 2. P. 30-37. URL: https://vestnik5.geogr.msu.ru/jour/ article/view/202?locale=ru_RU (accessed: 26.06.2021). (In Russ.)

Денисенко М.Б., Чудиновских О.С. К вопросу об организации миграции медицинских работников // Современные исследования миграции населения / под общ. ред.: Е. В. Донец, О.С. Чудиновских. М.: Экономический факультет МГУ им. М. В. Ломоносова, 2015. («Демографические исследования». Вып. 26) C. $31-49$.

Denisenko M.B., Chudinovskikh O.S. (2015) To the Question of Organizing the Migration of Medical Workers. In: Donets E.V., Chudinovskikh O.S. (eds.) Contemporary Research 
of Migration: Collection of Articles. Moscow: Faculty of Economics, Lomonosov Moscow State University. (“Demographic Research”. Vol. 26). P. 31-49. (In Russ.)

Зубаревич Н. В. Трансформация сельского расселения и сети услуг в сельской местности // Известия РАН. Сер. Географическая. 2013. № 3. С. 26-38. https:// doi.org/10.15356/0373-2444-2013-3-26-38.

Zubarevich N. V. (2013) Transformation of Rural Settlement Pattern and Service Network in Rural Areas. Izvestiya Rossiiskoi Akademii Nauk. Seriya Geograficheskaya. No. 3. P. 26-38. https://doi.org/10.15356/0373-2444-2013-3-26-38. (In Russ.)

Зубаревич Н.В. Развитие российского пространства: барьеры и возможности региональной политики // Мир новой экономики. 2017. № 2. C. 46-57. URL: https://wne.fa.ru/jour/article/view/125 (дата обращения: 28.06.2021).

Zubarevich N. V. (2017) Development of the Russian Space: Barriers and Opportunities for Regional Policy. The World of New Economy. No. 2. P. 46-57. URL: https://wne. fa.ru/jour/article/view/125 (accessed: 28.06.2021). (In Russ.)

Карачурина Л.Б. Привлекательность центров и вторых городов регионов для внутренних мигрантов в России // Известия РАН. Серия Географическая. 2020. № 4. C. 506-516. https://doi.org/10.31857/S258755662004007X.

Karachurina L. B. (2020) The Attractiveness of the Centers and Secondary Cities of the Regions for Internal Migrants in Russia. Izvestiya Rossiiskoi Akademii Nauk. Seriya Geograficheskaya. No. 4. P. 506-516. https://doi.org/10.31857/ S258755662004007X. (In Russ.)

Флоринская Ю.Ф, Карачурина Л.Б. Новая волна интеллектуальной эмиграции из России: мотивы, каналы и механизмы // Мониторинг общественного мнения: экономические и социальные перемены. 2018. № 6. С. 183-200. https:// doi.org/10.14515/monitoring.2018.6.09.

Florinskaya Y. F., Karachurina L. B. (2018) New Wave of Intellectual Emigration from Russia: Motives, Channels and Mechanisms. Monitoring of Public Opinion: Economic and Social Changes. No. 6. P. 183-200. https://doi.org/10.14515/ monitoring.2018.6.09. (In Russ.)

Козлов Д. В., Платонова Д. П., Лешуков О. В. Где учиться и где работать: межрегиональная мобильность студентов и выпускников университетов. М.: НИУ ВШЭ, 2017. Kozlov D. V., Platonova D. P., Leshukov O. V. (2017) Where to Study and Where to Work: Interregional Mobility of University Students and Graduates. Moscow: NRU HSE. (In Russ.)

Комаров Ю.М. О подготовке врачебных кадров в Российской Федерации // Медицина. 2013. № 3. С. 1-11. URL: https://www.fsmj.ru/015121.html (дата обращения: 28.06.2021).

Komarov J.M (2013) On Training of Medical Staff in Russian Federation. Medicine. No. 3. P. 1-11. URL: https://www.fsmj.ru/015121.html (accessed: 28.06.2021). (In Russ.)

Мкртчян Н. В. Центро-периферийные миграционные взаимодействия в Центральной России //Научные труды: Институт народнохозяйственного прогнозиро- 
вания PAH. 2012. № 10. С. 483-498. URL: https://ecfor.ru/publication/tsentroperiferijnye-migratsionnye-vzaimodejstviya/ (дата обращения: 28.06.2021).

Mkrtchyan N. V. (2012). Center and Periphery Migrational Interrelation in Central Russia. Scientific Works: Institute for Economic Forecasting RAS. No. 10. P. 483-498. URL: https://ecfor.ru/publication/tsentro-periferijnye-migratsionnye-vzaimodejstviya/ (accessed: 28.06.2021). (In Russ.)

Население России 2017: двадцать пятый ежегодный демографический доклад / отв. ред.: Захаров С.В. М.: Издательский дом НИУ ВШЭ, 2019. https://doi.org/ 10.17323/978-5-7598-2124-3.

Zakharov S. V. (ed.) (2019) Russia's Population in 2017: 25rd Annual Demographic Report National Research University Higher School of Economics. Moscow: HSE Publishing House. https://doi.org/10.17323/978-5-7598-2124-3. (In Russ.)

Нефедова Т. Г., Трейвиш А.И. Россия: между двумя столицами: специфика территориальных сдвигов // Региональные исследования. 2013. № 4. C. 31-43. URL: http://media.geogr.msu.ru/RI/RI_2013_04(42).pdf (дата обращения: 29.06.2021). Nefedova T. G., Treyvish A. I. Russia Between Its Two Capitals: The Specifics of Territorial Shifts. Regional Studies. No. 4. P. 31-43. URL: http://media.geogr.msu.ru/RI/ RI_2013_04(42).pdf (accessed: 29.06.2021). (In Russ.)

Оксиненко В.Г. Миграционные намерения студентов выпускных курсов медицинских вузов в России и некоторых стран СНГ // Население и экономика. 2019. Т. 3. № 4. C. 65-85. https://doi.org/10.3897/popecon.3.e49754.

Oksinenko V.G. (2019) Migration Intentions of Graduate Students of Medical Universities in Russia and Some Cis Countries. Population and Economics. Vol. 3. No. 4. P. 65-85. https://doi.org/10.3897/popecon.3.e49754. (In Russ.)

Рыбаковский Л.Л. Факторы и причины миграции населения, механизм их взаимосвязи //Народонаселение. 2017. T. 20. № 2. С. 51-61. URL: https://www.jour. fnisc.ru/index.php/population/article/view/6538 (дата обращения: 29.06.2021). Rybakovsky L. L. (2017). Factors and Causes of Population Migration, the Mechanism of Their Relationship. Population. Vol. 20. No. 2. P. 51-61. URL: https://www.jour. fnisc.ru/index.php/population/article/view/6538 (accessed: 29.06.2021). (In Russ.)

Сиротко М.Л., Богатырева Г.П., Корендясов П. П. Влияние миграции выпускников медицинского вуза на обеспеченность врачебными кадрами в Самарской области //Бюллетень Национального научно-исследовательского института общественного здоровья имени Н. А. Семашко. 2015. № 7. С. 82-93. URL: https://nriph. ru/images/assets/files/archive/2015/byulleten_7_2015.pdf (дата обращения: 29.06.2021).

Sirotko M. L., Bogatyreva G. P., Korendyasov P.P. (2015) Influence of Medical School Graduates Migration on Physician Staffing in the Samara Region. Bulletin of the National Research Institute of Public Health named after N. A. Semashko. No. 7. P. 8293. URL: https://nriph.ru/images/assets/files/archive/2015/byulleten_7_2015.pdf (accessed: 29.06.2021). (In Russ.) 
Тарасенко Е. А., Хорева О.Б. Экономическое стимулирование для устранения дефицита медицинских кадров в сельских территориях // Вопросы государственного и муниципального управления. 2016. № 4. C. 117-142. URL: https://vgmu.hse.ru/ 2016-4/199078563.html (дата обращения: 29.06.2021).

Tarasenko, E. A. Khoreva, O.B. (2016) Economic Incentives for Medical Personnel Deficit Elimination in Rural Areas. Public Administration Issues. No. 4. P. 117-142. URL: https://vgmu.hse.ru/2016-4/199078563.html (accessed: 29.06.2021). (In Russ.)

Ткаченко А.А., Смирнов И.П., Фомкина А. А. Подходы к оценке территориально-урбанистической структуры нестоличных областей Центральной России // Региональные исследования. 2015. № 4. С. 105-112.

Tkachenko A. A., Smirnov I. P., Fomkina A. A. (2015) The Approaches to the Assessment of the Territorial-Urban Structure for Non-Capital Central Russia Regions. Regional Studies. No. 4. P. 105-112. (In Russ.)

Ткаченко А. А., Фомкина А. А. Глубинка Центральной России: опыт формализованного выделения // Российская глубинка: модели и методы изучения. М.:Эслан., 2012. С. $49-62$.

Tkachenko A. A., Fomkina A. A. (2012) A Province of Central Russia: Experience of Formal Identification In: Russian Hinterland: Models and Methods of Study. Moscow: Eslan. P. 49-62. (In Russ.)

Цапенко И.П., Сауткина В.А. Глобальные миграции и экономика здравоохранения //Terra economicus. 2018. Т. 16. № 1. С. 84-100. https://doi.org/10.23683/ 2073-6606-2018-16-1-84-100.

Tsapenko I. P., Sautkina V.A. (2018) Global Migrations and Health Economics. Terra economicus. Vol. 16. No. 1. P. 84-100. https://doi.org/10.23683/2073-6606-201816-1-84-100. (In Russ.)

Шейман И. М., Сажина С. В. Кадровая политика в здравоохранении: как преодолеть дефицит врачей // Мир России: Социология, этнология. 2018. Т. 27. № 3. C. 130-153. https://doi.org/10.17323/1811-038X-2018-27-3-130-153.

Sheiman I. M., Sazhina S. V. (2018) Human Resource Policies in the System of Health Provision: Overcoming the Shortage of Physicians. Universe of Russia. Sociology. Ethnology. Vol. 27. No. 3. P. 130-153. (In Russ.) https://doi.org/10.17323/1811038X-2018-27-3-130-153. (In Russ.)

Шишкин С. В., Шейман И. М., Абдин А.А., Боярский С.Г., Сажина С. В. Российское здравоохранение в новых экономических условиях: вызовы и перспективы. М. : Издательский дом НИУ ВШЭ, 2016.

Shishkin S. V., Sheiman I. M., Abdin A. A., Boyarsky S. G., Sazhina S. V. (2016) Russian Health Care in New Economic Conditions: Challenges and Prospects. Moscow: NRU HSE Publishing House. (In Russ.)

Штейнберг И.Е. Логические схемы обоснования выборки для качественных интервью: “восьмиоконная" модель // Социология: методология, методы, математическое моделирование (4M). 2014. № 38. С. 38-71. URL: https://www.isras.ru/ index.php?page_id=2384\&id=3770\&l= (дата обращения: 29.06.2021). 
Steinberg I. Ye. (2014) Logical Schemes for Substantiating a Sample for Qualitative Interviews: An "Eight-Window" Model. Sociology: Methodology, Methods, Mathematical Modeling (Sociology: 4M). No. 38. P. 38-71. URL: https://www.isras.ru/index. php?page_id=2384\&id=3770\&l= (accessed: 29.06 .2021$)$. (In Russ.)

Ядов В.А. Стратегии и методы качественного анализа данных //Социология: методология, методы, математическое моделирование (4M). 1991. № 1. С. 14-31. URL: https://www.isras.ru/index.php?page_id=2384\&id=3835\&type=ојs (дата обращения 25.06.2021).

Yadov V. A. (1991) Strategies and Methods of Qualitative Data Analysis. Sociology: Methodology, Methods, Mathematical Modeling (4M). No. 1. P. 14-31. URL: https:// www.isras.ru/index.php?page_id=2384\&id=3835\&type=ojs (accessed: 25.06 .2021 ). (In Russ.)

Adkoli B. (2006) Migration of Health Workers: Perspectives From Bangladesh, India, Nepal, Pakistan and Sri Lanka. Regional Health Forum. Vol. 10. No. 1. P. 49-58.

Akl E., Maroun N., Major S., Afif C., Chahoud B., Choucair J., Sacr M., Schünemann H. (2007) Why Are You Draining Your Brain? Factors Underlying Decisions of Graduating Lebanese Medical Students to Migrate. Social Science \& Medicine. Vol. 64. No. 6. P. 1278-1284. http://dx.doi.org/10.1016/j.socscimed.2006.10.021.

Astor A., Akhtar T., Matallana M. A., Muthuswamy V., Olowu F. A., Tallo V., Lie R. (2005) Physician Migration: Views From Professionals in Colombia, Nigeria, India, Pakistan and the Philippines. Social Science and Medicine. Vol. 61. No. 12. P. 2492-2500. http://dx.doi.org/10.1016/j.socscimed.2005.05.003.

Awases M., Gbary A., Nyoni J., Chatora R. (2004) Migration of Health Professionals in Six Countries: A Synthesis Report. World Health Organization. Vol. 65. P. 38-42. URL: https://www.afro.who.int/publications/migration-health-professionals-six-countriessynthesis-report (accessed: 29.06.2021).

Baer L., Ricketts T., Konrad T., Mick S. (1998) Do International Medical Graduates Reduce Rural Physician Shortages? Medical Care. Vol. 3. No. 11. P. 1534-1544. http://dx.doi.org/10.1097/00005650-199811000-00003.

Botezat A., Ramos R. (2020) Physicians' Brain Drain-a Gravity Model of Migration Flows. Globalization and Health. Vol. 16. No. 1. P. 1-13. http://dx.doi.org/10.1186/ s12992-019-0536-0.

Brugha R., McAleese S., Dicker P., Tyrrell E., Thomas S., Normand C., Humphries N. (2016) Passing Through-Reasons Why Migrant Doctors in Ireland Plan to Stay, Return Home or Migrate Onwards to New Destination Countries. Human Resources for Health. Vol. 14. No. 1. P. 1-35. http://dx.doi.org/10.1186/s12960-016-0121-z.

De Haas H. (2010) Migration and Development: A Theoretical Perspective 1. International Migration Review. Vol. 44. No. 1. P. 227-264. http://dx.doi.org/10.1111/j.17477379.2009.00804.x.

Dubois C.-A., Nolte E., McKee M. (2005) Human Resources for Health in Europe. Maidenhead: McGraw-Hill Education Blacklick. 
George A., Blaauw D., Thompson J., Green-Thompson L. (2019) Doctor Retention and Distribution in Post-Apartheid South Africa: Tracking Medical Graduates (2007-2011) From One University. Human Resources for Health. Vol. 17. No. 1. P. 100-109. http:// dx.doi.org/10.1186/s12960-019-0439-4.

George G., Atujuna M., Gow J. (2013) Migration of South African Health Workers: The Extent to Which Financial Considerations Influence Internal Flows and External Movements. BMC Health Services Research. Vol. 13. No. 1. P. 297-305. http:// dx.doi.org/10.1186/1472-6963-13-297.

Goštautaitè B., Bučiūnienè I., Milašauskienè Ž., Bareikis K., Bertašiūtè E., Mikelionienè G. (2018) Migration Intentions of Lithuanian Physicians, Nurses, Residents and Medical Students. Health Policy. Vol. 122. No. 10. C. 1126-1131. http://dx.doi.org/10.1016/j. healthpol.2018.07.001.

Han G., Humphreys J. (2006) Integration and Retention of International Medical Graduates in Rural Communities: A Typological Analysis. Journal of Sociology. Vol. 42. No. 2. P. 189-207. http://dx.doi.org/10.1177/1440783306064951.

Harris J., Todaro M. (1970) Migration, Unemployment and Development: A Two-Sector Analysis. The American Economic Review. Vol. 60. No. 1. P. 126-142.

Lee E. (1966) A Theory of Migration. Demography. Vol. 3. No. 1. P. 47-57. http:// dx.doi.org/10.2307/2060063.

Mbemba G., Gagnon M., Hamelin-Brabant L. (2016) Factors Influencing Recruitment and Retention of Healthcare Workers in Rural and Remote Areas in Developed and Developing Countries: An Overview. Journal of Public Health in Africa. Vol. 7. No. 2. P. 61-66. http://dx.doi.org/10.4081/jphia.2016.565.

Syed N., Khimani F., Andrades M., Ali S., Paul R. (2008) Reasons for Migration among Medical Students from Karachi. Medical education. Vol. 42. No. 1. P. 61-68. http:// dx.doi.org/10.1111/j.1365-2923.2007.02904.x.

Vujicic M., Zurn P., Diallo K., Adams O., Dal Poz M. R. (2004) The Role of Wages in the Migration of Health Care Professionals from Developing Countries. Human Resources for Health. Vol. 2. No. 1. P. 3-17. http://dx.doi.org/10.1186/1478-4491-2-3.

Whittal A., Boeckmann M. (2018) International Recruitment and Migration of Physicians and Health Workers: A Qualitative Scoping Review of Public Health Literature. Ethik in der Medizin. Vol. 30. No. 3. P. 263-283.

Wismar M., Maier C., Glinos I., Dussault G., Figueras J. (2011) Health Professional Mobility and Health Systems. Evidence from 17 European Countries. Copenhagen: WHO Regional Office for Europe.

Yow A., Garces-Ozanne A., Audas R. (2015) Carousel and Conveyor Belt: The Migration of Doctors in New Zealand. Labour \& Industry: A Journal of the Social and Economic Relations of Work. Vol. 25. No. 3. P. 219-234. http://dx.doi.org/10.1080/103017 63.2015.1081479. 